\title{
Contraceptive method mix in the context of family planning programmes in developing countries
}

\author{
Lilia V. Boglaeva ${ }^{1}$ \\ 1 Lomonosov Moscow State University, Moscow, 119991, Russia
}

Received 25 June 2021 • Accepted 03 August 2021 • Published 30 September 2021

Citation: Boglaeva LV (2021) Contraceptive method mix in the context of family planning programmes in developing countries. Population and Economics 5(3): 56-75. https://doi.org/10.3897/popecon.5.e70669

\begin{abstract}
The paper examines the formation of the contraceptive method mix within the framework of family planning programmes in developing countries, taking into account the influence of socio-demographic, economic, and behavioural factors. The study has shown that the impact of family planning programmes on changes in the method mix is ambiguous and depends on the time of the start of the programme, the region of the country, the level of medical service development, and other factors. The paper also analyzes the correlation between the peculiarities of the method mix in a country and abolishment of particular methods. The author reveals that in developing countries the poorest users of young reproductive age are the most vulnerable and prone to contraception discontinuation. It is these population groups that experience the most dissatisfaction with family planning.
\end{abstract}

\section{Keywords}

family planning programme, developing countries, contraceptive method mix, prevalence of contraception, fertility, demographic policy, contraceptive method skew

JEL codes: J13

\section{Introduction}

As defined by the World Health Organization (WHO), family planning allows people to have the desired number of children and determine the intervals between their births, as well as choose the means by which this can be achieved (WHO. Family planning, n.d.). These means primarily include various methods of contraception.

A variety of contraceptive methods are available to the population who practice birth control. The contraceptive method mix, by which we mean the distribution of users by methods, depends on the individual capabilities and preferences. As noted in (Bertrand 
et al. 2000), "there is currently no "ideal" method mix recognized by the international community; however, there is a reason for concern when one or two methods predominate in a given country» (see also Ali at al. 2012). This leads to a method skew, which indicates a systematic restriction of choice for the population.

Historically, certain methods have been favoured in particular countries. This has led to a deformation in the method mix and, consequently, to less satisfaction of the demand for contraceptives or even the discontinuation of their use by women and couples who need contraceptive protection. Discontinuation contributes to slowing down the decline in fertility (which many developing countries regard as a developmental goal), while triggering an increase in unwanted pregnancies and induced abortions. At the same time, family planning programmes are a factor in the formation of a balanced contraceptive method mix, which increases the overall prevalence of contraception and potentially reduces the number of unwanted pregnancies and induced abortions. Adhering to the latter argument, the author of this study turns to the analysis of the macro and micro level factors influencing method mix. Such an analysis is one of the necessary stages on the way to the development and subsequent implementation of public policy measures aimed at increasing the satisfaction of the population needs in family planning.

The author of this paper focuses on the following research questions:

1. Which macro level factors correlate with the contraceptive method skew in different countries? How significant are family planning programmes in smoothing out the skew?

2. What micro and macro factors are responsible for structural changes in contraceptive methods in developing countries?

\section{Family planning programmes and the demand for contraception in developing countries}

Family planning programmes (hereinafter - FPP) exist in most developing countries in Asia, Africa, Latin America, and the Middle East. National government programmes are implemented by ministries of health care or other government agencies. For example, in Mexico and Peru, these are national welfare programmes; in Indonesia, services are provided by specific national organizations, independent of the ministry of health care (Morris 2000). In other countries, especially in sub-Saharan Africa, family planning services are integrated into maternal and child healthcare programmes. There are also many nongovernmental family planning programmes, the most common of which are those of the national associations of the International Planned Parenthood Federation (IPPF). Private practitioners and pharmacies serve as complementary channels for the distribution of contraception and family planning services in most countries.

The issue of the relationship between family planning programmes and the fertility rate has been in the focus of interest of demographers and sociologists for many years. In analyzing the effectiveness of family planning, in particular the use of contraceptive methods, research identifies social, cultural, economic, organizational and even political factors (Morris 2000). They all affect the need for children and the practice of birth control, as well as related demographic policies and family planning programmes. However, this influence is not direct, but is cariied out through a set of factors called proximate determinants of fertility, which include: the proportion of married people (factors of susceptibility to conception), 
the prevalence of induced abortion and contraception (factors of conscious control over marital fertility), postpartum amenorrhea, sterility (measured by the proportion of women who have never had children by the age of 50), the duration of the fertile period (factors of natural marital fertility) (Bongaarts, 1978; Davis and Blake, 1956).

Similarly, family planning programmes use indicators such as the prevalence of one or another contraceptive method and structure of applied method to assess «how well they are doingж In addition, donors have used data fertility changes, contraceptive prevalence, and unmet need for family planning to show whether programs are working and to make the case for continued funding of international population assistance and in policy discussions with leaders of developing countries» (Seltzer, 2002: 23).

In China and Brazil, the high proportion of modern methods in the structure of contraception is combined with its high overall prevalence. In China, modern methods are preferred by $95 \%$ of users (in fact, in 2017 , out of $84.5 \%$ of women of reproductive age who are in partnerships and using contraception, 80.5\% used modern methods), in Brazil - 97\% (80.2\% and $77.7 \%$ respectively in 2013). The opposite situation is observed in Libya: with a relatively low overall prevalence of contraception, almost half of the users prefer traditional methods of family planning, while modern methods account for 54\% in the method mix (in 2014, out of $27.7 \%$ of users, $16.3 \%$ turned to modern methods). Fig. 1 shows the distribution of 59 developing countries according to deviations from the average proportion of users of all methods of contraception and the proportion of modern methods in its structure. The overall contraceptive prevalence rates (X-axis) do not show clear trends across regions: each has countries

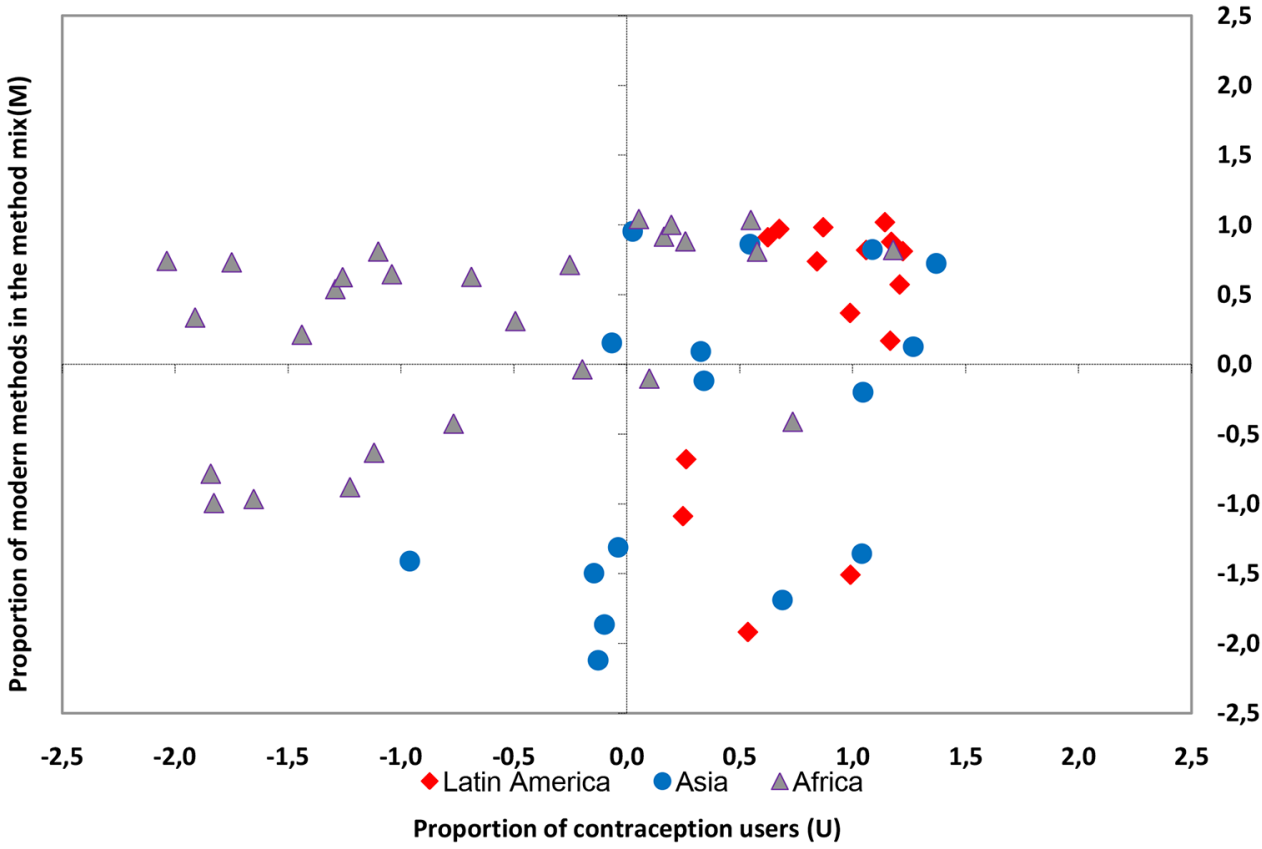

Fig. 1. The prevalence of contraception and the proportion of modern methods in the method mix (relative deviation from the sample mean, measured in standard deviations). Source: compiled by the author based on (World Contraceptive Use 2020). Note: Average values for 59 countries used for clustering were: overall prevalence $-54.93 \%$, share of users employing modern methods $-48.66 \%$, and traditional methods $-6.28 \%$. 
with a proportion of users below the sample average and countries with a higher rate. As for the proportion of modern methods in the method mix (Y-axis), for all Latin American countries it is above the average value for the sample, and in Asia (with the exception of Pakistan) it is either above the average value or close to it. The strongest differentiation among countries in the share of modern methods in the structure of contraception is observed in Africa: from Botswana, Morocco and Zimbabwe, where both rates are above the sample average, to Benin, Niger and the Central African Republic, where they are below average.

Although the prevalence of contraception in the world is steadily increasing, unmet need for family planning remains an important problem in many countries (Sedgh et al. 2016). The concept of unmet need for family planning (unmet need for contraception) has evolved significantly since its initial definition as the gap between actual and preferred use of contraception. Over the past decade, a number of refinements have been made, including in the way this indicator is measured. The unmet need for family planning now illustrates the gap between women's reproductive intentions and their contraceptive behaviour. It is defined as the proportion of women who want to stop or postpone childbirth, but do not use any contraceptive method (United Nations 2019). In 2016, an estimated $21 \%$ of women of reproductive age in developing countries had an unmet need for contraception (Sedgh et al. 2016). One of the reasons for this situation is the restrictions on the use of contraceptives, which many women in developing countries continue to face, including the lack of access to health care of adequate quality. Reducing unmet needs for family planning is a concept that combines both national demographic goals and the rights of individuals, as reflected in the agenda of the United Nations International Conference on Population and Development (ICPD) in Cairo (United Nations 1995), relevant up to the present moment.

\section{Contraceptive method mix and individual choice}

The term method mix refers to the combination of contraceptives available within and beyond family planning programmes. The optimal method mix for a country-specific programme will depend on the needs of the users and the resources of the programme. A method mix that is appropriate for one programme and one country may not be appropriate for another. A good contraceptive method framework is one that includes multiple methods and takes into account the needs and preferences of all segments of the population in a country (WHO 1994).

One of the central characteristics of high-quality health care is the availability of methods adequate to the needs of the country's population and particular users. The wide range of available contraceptive methods is considered important as contraceptive users are empowered to exercise the choice enshrined at the UN International Conference on Population and Development in 1994. The choice of method depends, among other things, on the preference of the woman or the couple regarding the number of children and the intervals between their births. For example, the sterilization method (both female and male) is usually used if the couple's reproductive goals have been achieved, that is, they have already had

1 «Everyone has the right to the enjoyment of the highest attainable standard of physical and mental health. States should take all appropriate measures to ensure, on a basis of equality of men and women, universal access to health-care services, including those related to reproductive health care, which includes family planning and sexual health» (United Nations 1995: 12). 
the desired number of children; barrier methods have a dual function protecting users from unintended pregnancies as well as sexually transmitted infections (STIs) and HIV. Method selection is also important for user satisfaction and duration of method use, as providing the preferred method is associated with more sustainable contraceptive use (Pariani et al. 1991). In addition to meeting user needs, the availability and accessibility of a wide range of contraceptive methods can lead to higher overall contraceptive prevalence (Ross et al. 2013).

Despite the wide availability and variety of modern methods of contraception, there are many examples of restriction in choice, which subsequently led to a skew in the method mix. A monograph on the activities of family planning programmes in developing countries (Seltzer 2002) notes that in many countries the pattern of contraceptive use is biased towards one or two methods (see examples in Fig. 2).

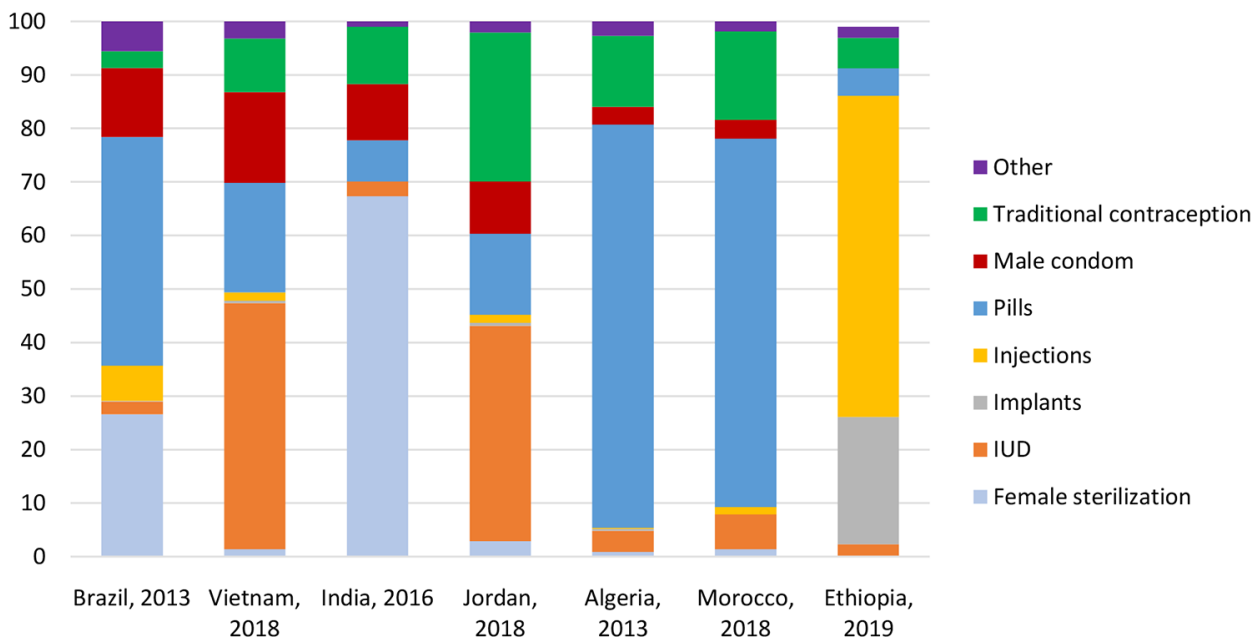

Fig . 2. Examples of countries with a skew in method mix. Source: compiled by the author based on (World Contraceptive Use 2020)

The shift in structure towards individual methods in family planning programmes occurs for various reasons. These include the cost and complexity of a range of contraceptive methods, and how methods such as IUD and sterilization are considered more effective in preventing pregnancy and therefore effective in meeting demographic goals. A criticism of this approach is that methods that are effective in achieving policy goals do not always meet the reproductive health needs, preferences and rights of women and couples (Gipson et al. 2008).

A number of studies have attempted to determine both the method mix skew and the list of factors that correlate with the structure of the methods used. Thus, Bertrand defined a combination of methods (Bertrand et al. 2000), which can be taken as a standard. This is not an ideal or suitable combination for all countries without exception, but it is the method mix closest to even, calculated on the basis of DHS data in developing countries (Table 1). The same study developed and assessed the Index of Dissimilarity, which shows the extent to which the method mix in a country is subject to skew; this indicator allows cross-country comparisons. 
Table 1. Distribution of methods, taken as a standard for measuring the Index of Dissimilarity

\begin{tabular}{cc}
\hline Contraceptive method & Proportion of users, \% \\
\hline Pills & 22.2 \\
Female sterilization & 21.9 \\
Traditional methods & 17.8 \\
Barrier methods & 14.3 \\
IUD & 11.0 \\
Injections & 10.8 \\
\hline
\end{tabular}

Source: (Bertrand et al. 2000).

\section{Discontinuation of methods as a factor of contraception structure change}

Despite the reinforcement of family planning programmes, in developing countries, an average of 70 million unplanned pregnancies are registered annually, of which a significant proportion (30\%) are due to ineffective contraception among women using one method or another (Polis et al. 2016). The notion of inefficiency can be interpreted in two ways. The first is the refusal to use contraception associated directly with dissatisfaction with the method. For example, identified medical contraindications during use, unwillingness to follow instructions for use, high price, etc. The second is the so-called contraceptive «misfire», that is, the onset of pregnancy during the use of the method due to its ineffectiveness or misuse. Often, discontinuation of contraception is assessed as ineffectiveness of the family planning programme. Refusal to use the method can also result in deformation in the structure of the applied methods.

Research to assess the frequency and likelihood of certain contraceptive methods discontinuation in developing countries draws heavily on data from the Demographics and Health Survey (DHS). For example, DHS data have provided an assessment of the causes as well as the consequences of discontinuing contraception for married women (Ali et al. 2012). The authors of this study note that median contraceptive misfire rates among women in developing countries were $1.1 \%$ for IUDs, $1.5 \%$ for injectables, $5.6 \%$ for pills, $7.6 \%$ for male condoms, and 17,4\% for intermittent abstinence. Another study (Bradley et al. 2019) assesses contraceptive ineffectiveness for women in all types of partnerships, albeit limiting the analysis to particular subgroups with specific socio-demographic and economic characteristics or a list of countries. By censoring DHS data to correlate the dates of the method misfire with the child's date of birth, the authors were able to show that the user was deliberately refusing to use a particular method of contraception. The results of this work seem to be one of the most accurate and, as of today, most relevant.

\section{Data, methods, and hypotheses}

The purpose of this study is to assess the correlation of the availability of family planning programmes with the method mix in a number of developing countries. The author traces 
how the ratio of methods changes in the presence of an active family planning programme in the country, depending on the period of the beginning of the implementation of this programme, and also identifies the categories of the population that are more likely to discontinue the use of contraception; these groups should be considered as target in the implementation of the policy in the field of family planning.

\section{Relation of method mix skew with the family planning programme onset}

If family planning programmes can increase the overall prevalence of contraception in the population, can they also have a transformative effect on the method mix? To answer this question, the author of this study develops an approach, in which it is checked how the date of the FPP onset in the country and the contraceptive method mix skew are interconnected. The skew hereinafter will be understood as the deviation from the average for ten developing countries with the distribution of contraceptive methods closest to the uniformity given in (Bertrand et al. 2000). By this value, the author does not mean a method mix that is «ideal» or suitable for everyone; this indicator serves as a research tool and is used for the convenience of testing the following hypothesis: the period of the start of family planning programmes in the country is positively correlated with the method mix skew (Hypothesis 1). A qualitative assessment of the method mix is possible only in terms of its effectiveness in preventing unplanned pregnancies, which is beyond the scope of this article.

To test the first hypothesis, the author identifies the correlates of the method mix skew in a multivariate regression using the least-squares method.

It is not possible to directly assess the correlation between the features of the FPP functioning and the method mix. For this reason, in this study, the interaction of variables will be considered through indirect indicators. The Index of contraceptive Dissimilarity (ID), developed within the framework of a family planning study (Bertrand et al. 2000), was selected as a dependent variable. It is relatively easy to calculate and interpret. By definition, it is a cumulative measure of the difference between two distributions based on the absolute differences between the percentages for each category.

$$
\mathrm{ID}=\frac{1}{\mathrm{~N}} \sum_{\mathrm{i}=1}^{\mathrm{N}}\left|\mathrm{a}_{\mathrm{i}}-\mathrm{b}_{\mathrm{i}}\right|
$$

where $\mathrm{N}$ is the number of contraceptive methods used in the analysis, $\mathrm{a}_{\mathrm{i}}$ is the share of method $i$ in the country's contraceptive structure, $b_{i}$ is the share of method $i$ in the structure of standard distribution of contraception.

One of the four components of the Family Planning Effort Index (FPE) is the proxi variable for measuring the effectiveness of family planning programmes. This metric was developed in 1972 as part of a United Nations Population Fund (UNFPA) project. The index is calculated on the basis of thirty indicators of the effectiveness of family planning programmes, broken down into four categories: policy attitudes, services, performance assessment, and access of the population to methods of contraception. In the context of this study, the variable population access to contraceptive methods is of interest. Qualitatively, this indicator reflects the wide variety of contraceptive methods available to users of family planning programmes.

Information on the beginning of the implementation of family planning programmes in developing countries included in the analysis is given in Table 2. 
Table 2. Year of commencement of FPP implementation in developing countries in the sample for testing Hypothesis 1

\begin{tabular}{ll|ll|lc}
\hline \multicolumn{1}{c|}{ Country } & Year & \multicolumn{1}{|c|}{ Country } & Year & \multicolumn{1}{c}{ Country } & Year \\
\hline India & 1952 & Malaysia & 1966 & Mexico & 1974 \\
Bangladesh & 1952 & Tanzania & 1966 & Senegal & 1982 \\
Pakistan & 1952 & Tunisia & 1966 & Peru & 1983 \\
Egypt & 1954 & Brazil & 1967 & Bolivia & 1986 \\
Liberia & 1956 & Paraguay & 1968 & Dominican & 1986 \\
Algeria & 1962 & Ghana & 1970 & Republic & \\
Costa Rica & 1962 & Indonesia & 1970 & Mali & 1990 \\
Thailand & 1963 & Cuba & 1970 & Iraq & 1993 \\
Turkey & 1963 & Cameroon & 1971 & Philippines & 1993 \\
Nigeria & 1964 & Central African & 1972 & Vietnam & 1994 \\
Zimbabwe & 1965 & Republic & & & 1994 \\
Iran & 1966 & Ealawi & 1974 & Namibia & \\
\hline
\end{tabular}

Source: compiled by the author based on the official family planning documents of the countries.

Research shows that early FPPs have historically demonstrated adherence to certain contraceptive methods (method-bias). An example is the prevalence of female sterilization in India, the first country in the world to launch a family planning programme.

The expansion of the regression is carried out by a successive inclusion of the following independent variables into the model:

1. fertility rate (total fertility rate for the years for which the surveys were carried out);

2. level of economic development (gross national income at purchasing power parity per capita for the years for which the surveys were carried out);

3. characteristics of the medicine level of development (life expectancy at birth) and coverage of the population by the health care system (number of doctors per 100,000 population);

4. dummy variables of the region where the country is located (Asia, Latin America, and Africa) and the prevailing religion (Christianity, Islam, Catholicism, other religions); these variables are included to account for differences and specificities identified during the review of the scientific literature on the topic.

In order to test the first hypothesis, data were collected from thirty-four developing countries (see Table A1 of the Appendix, Countries column), which meet two criteria: population of at least 1 million and at least one DHS survey in 1970 to 2020. The introduction of criteria in the selection of countries is intended to reduce the likelihood of bias in the results.

The UN Development Programme World Contraceptive Use 2020 database, which provides a comparable and up-to-date set of data on family planning indicators for women of 
reproductive age (from 15 to 49 years) for the period from 1950 to 2019 is the source for calculating the index of contraceptive dissimilarity (ID).

For further analysis, six methods of contraception were selected, towards which there are most often skews in developing countries, namely: female sterilization, pills, injections, IUDs, barrier and traditional methods.

The results of calculating the ID are presented in Table P1 in the Appendix to the paper. Comparison of the obtained values with the same indicator for surveys conducted before 2000 (Bertrand et al. 2000) shows that over the past twenty years, in many countries, there has been a tendency towards smoothing deformations in the method mix. This can also be considered an argument in favour of including the variable of the period when family planning programmes start.

\section{Changes in method mix due to refusal discontinuation of method use}

The second part of the study examines how the structure of contraceptive methods changes in the event of discontinuation in use of a particular method under the influence of the socio-demographic and economic characteristics of the individual, as well as due to the place of obtaining the method or service. This includes all possible reasons for discontinuation, including contraception misfire, since the data was not censored ${ }^{1}$. In the latter case discontinuation is perceived as ineffectiveness of the birth control method, and not of the family planning programme in general.

The hypothesis of this part of the study is formulated as follows: the probability of discontinuation of using the same method of contraception depends on the socio-demographic and economic characteristics of the individual, as well as on the place of receipt of the service (state medical institution, nongovernmental public organization, pharmacy, etc.; Hypothesis 2).

To test the second hypothesis, the author applied a multilevel model of proportional risks for the probability of discontinuation of using contraception for each method with fixed effects and logarithm of time (Rabe-Hesketh and Skrondal 2012: 843), during which each woman is at risk of discontinuation - with a temporary at intervals of three months.

The model for analysis, derived from a review of the literature (Bradley et al. 2019) and modified for the purposes of this study, is as follows:

$$
\begin{gathered}
\ln \left(\mu_{\mathrm{ij}}\right)=\ln \left(\mathrm{t}_{\mathrm{ij}}\right)+\alpha_{\mathrm{sj}}+\beta_{\mathrm{n}} \gamma_{\mathrm{n}}+\mathrm{e}_{\mathrm{ij}} \\
\gamma_{\mathrm{n}} \text { takes values of: Age } \mathrm{e}_{\mathrm{ij}}, \text { Marital status }_{\mathrm{ijj}}, \text { Education }_{\mathrm{ij}} \text { ' } \\
\text { Well - being } \\
\text { ij }
\end{gathered}
$$

where $\mu_{\mathrm{ij}}$ is the indicator of discontinuation of use for the method, $t_{\mathrm{ij}}$ is the time lag of the episode of using the contraceptive method from the reproductive calendar of the $i$-th woman in country $j, a$ is interval-specific interception, which allows the underlying risk of failure for a given method of contraception to change every three months (Bradley et al. 2019), Age is the age of the $\mathrm{i}$-th woman in country j, Marital status is being married or consisting in some other partner alliance for the i-th woman in country $j$, Education ii the level of education achieved by a woman, Well-being ${ }_{i j}$ is an indicator of the socio-economic status of a woman

1 Hereinafter, censoring refers to the exclusion from the sample of women who have registered the fact of pregnancy during the use of contraception. It was carried out by comparing the contraceptive and reproductive calendars with a time lag for bearing and giving birth to a child. 
in a particular country, Place of residence is the area of residence of a woman, Source is the place of receipt and/or purchase of the service/method of contraception, is the probability of discontinuation of the use of contraception for different episodes of contraceptive use for the i-th woman for reasons that are not fixed by her age or other socio-demographic characteristics included in the model.

In order to test the second hypothesis within the model presented above, data from the DHS were selected for six developing countries (Table 3). The choice of countries, as in testing the first hypothesis, was carried out according to two criteria: population size of at least 1 million and at least one DHS wave from 1970 to 2020 .

Table 3. List of countries included in the sample for testing Hypothesis 2

\begin{tabular}{cc}
\hline Country & DHS survey period, years \\
\hline Bangladesh & 2014 \\
Colombia & 2010 \\
India & $2015-16$ \\
Philippines & 2017 \\
Senegal & $2010-2011$ \\
Zimbabwe & 2015 \\
\hline
\end{tabular}

Source: compiled by the author based on DHS data

Of interest for this study is information from surveys on the topic of family planning on the distribution of women aged 15-49 who were using contraception at the time of the survey, in accordance with the following characteristics: age, marital status, educational level, territory of residence and socio-economic status (wealth quintile). Based on the survey results, a retrospective contraceptive calendar was compiled for each woman, which enables calculating the frequency of discontinuation from the use of a contraceptive method according to the individual characteristics of the user.

The study also attempted to introduce a channel for the implementation of modern contraceptive methods into the model - through the distribution of users who receive contraception via public sector, private sector, or another source (for example, self-purchase or receipt from relatives or friends).

\section{Results}

To determine the presence and degree of correlation of family planning programmes with changes in the structure of contraceptive methods in developing countries, it is necessary to determine the skew towards certain methods in the considered countries. The countries in which this deformation is above average are of interest for this study; selection takes place by calculating the Index of Dissimilarity (ID), which was mentioned earlier.

The deviation of the specified index in absolute value from 1 means the predominance of one component or group. There are no countries for which the index takes a value equal to 1 
(absolutely uniform distribution of methods). It is also impossible to determine the optimal value of the index for contraceptive methods, as mentioned earlier; however, changes in the values of the index in the context of this study can be used as a tool for assessing the correlation of interest to us. With a decrease in the coefficient, one might mention smoothing of deformations, and with an increase - of an increasing bias towards one method or group of methods.

The coefficient was calculated for the period from 2011 to 2018 and grouped for Asia, Africa and Latin America (according to the UN methodology) to ease of comparison. The results are presented in Table $\mathrm{P} 1$ in the Appendix of the paper.

This intermediate stage also provides an opportunity to assess changes in the indicator over the past twenty years. Dynamics of the ID for 1982-1999 (Bertrand et al. 2000) shows values that are on average 2-5 units higher than those obtained in this study.

\section{Test results for Hypothesis 1}

To test the first hypothesis on the data and identify factors influencing changes in the method mix, several model specifications are used to avoid bias in the estimates.

The results of the regression analysis are presented in in Table P2 in the Appendix of the paper. In all specifications, the variable has a significant negative coefficient. A negative value indicates a decrease in the Index of Dissimilarity, that is, other things being equal, an increase in access to various methods of contraception as part of FPP efforts contributes to a more even distribution of the methods used among the population. This suggests that family planning programmes have a visible effect and contribute to a more balanced contraceptive structure in the long term. This result is consistent with the assumption that with an increase in the availability of a variety of contraceptive methods, the population will more evenly distribute their choices regarding contraception according to personal preferences, medical indications, and other factors.

The coefficients for the dummy variable of the period of the FPP onset also showed a significant correlation with the shifts in the method mix. However, all other things being equal, programmes that started before 1965 (the first family planning programme was officially launched in India in 1952) are more likely to show a negative correlation with method dissimilarity than programmes the beginning of implementation of which falls on the period 1966-1980. These results can be interpreted from two points of view. The first one considers the «flexibility» of FPP regarding the change of the historically dominant method (method-bias), as well as the inclusion in the programme of additional methods developed in later periods. The first FPPs, having achieved results from the implementation of individual methods, continue to rely only on them, while later programmes are ready to deliver a wider range of services to the population, taking into account the experience of the pioneers. The second point of view is based on the assumption of the source of funding: often FPPs are implemented with the support of international foundations and organizations that have their own preferences in the supply of one method or group of methods of contraception, which can also lead to shifts in the method mix in the absence of a choice for users. In 1966-1980 international economic crises weakened the financial support of FPPs, which may have led to a decline in the influence of providers of certain methods or services on the choice of the population. In the long term, this made it possible for the population to choose a method of contraception without regard to the dominant method, which, in turn, could have theoretically reduced the index of dissimilarity. However, both assumptions need to be tested and at this stage they can only act as hypotheses. 
Of the dummy variables, all categories were significant to varying degrees. The number of doctors per 100,000 population significantly correlates with changes in method mix, and a negative value indicates the possibility of a more even distribution of methods. The population living in the countries of Latin America, all other things being equal, distributes their preferences in the choice of the method of contraception more evenly than the respondents from the countries of Asia and Africa.

Based on the results of testing the first hypothesis, the following main conclusions can be drawn:

1. The presence of a family planning programme in the country has shown a correlation with deformation in the method mix. However, the nature of this correlation remains ambiguous and varies depending on the period of the start of the programme. The availability of a wider range of contraceptives in family planning programmes shows a positive correlation with the smoothing of deformations in the method mix. This suggests that family planning programmes are a significant tool through which one can influence the contraceptive behaviour of the population and, accordingly, the choice of individuals in favour of certain methods.

2. The territorial factor significantly interacts with the degree of deformation. Latin American countries have less dissimilarity in contraceptive patterns than African or Asian countries, which means they are more likely to promote different methods.

3. Religious affiliation as an ideological channel correlates with the choice of the contraceptive method. It can also be considered one of the exogenous factors that make it difficult to create a balanced method mix.

\section{Test results for Hypothesis 2}

The simulation results for testing the second hypothesis are presented in Table P3 in the Appendix of the paper. Adjusted contraceptive discontinuation rates during the first year of use of the method are employed here to compare populations. Some studies, however, interpret the results of such models as the likelihood that a woman using a particular method ceases to use it due to an unplanned pregnancy (WHO 1994; Ali et al. 2012). Otherwise, it can be considered as the likelihood of becoming pregnant when using contraception, which is an indicator of the failure of the contraceptive method. In the present study, the discontinuation rates are interpreted as the risk of refusal (in percentage) from the use of the contraceptive method for any reason, compared with the reference category during the first year of use with a time lag of three months. The results are applicable to populations living in developing countries.

The risk of discontinuation for any of the considered methods decreases as the age of the woman increases. All other things being equal, women over 40 are, on average, $80 \%$ less at risk of refusing to use contraception (for the IUD method, the estimate goes up to 99\%) than women under 20. The young population has the highest discontinuation rates. Women over 40 may no longer need contraceptive protection due to reduced fertility and continue to use the same method by inertia, considering it effective, since pregnancy does not occur. Here, one can take into account the high rates of indefinite methods (for example, sterilization) among the respondents of the older age group in the sample. The young population, on the other hand, is in search of a suitable method, younger respondents more often live out of permanent partnerships, therefore long-term contraception is not suitable for them and the change of methods is easier and more frequent. 
The impact of a woman's socioeconomic status cannot be interpreted unambiguously. Belonging to the poor quintile, all other things being equal, correlates with a higher risk of discontinuation of contraceptive pills and barrier methods. Given that these two methods have the greatest availability (including in terms of price), the obtained results require further research.

Populations receiving contraceptive methods - injections, IUDs, barrier methods through private sector institutions are less at risk of discontinuation than users whose source is public sector institutions.

The variable responsible for the presence of an official marriage, as expected, did not show a significant effect, which confirmed the need to include in the sample women who are in relationships of any form (cohabitation, guest marriage, etc.) and have a non-zero probability of an unplanned pregnancy.

Thus, Hypothesis 2 can be considered partially confirmed. The main conclusions from the results of this part of the study can be formulated as follows:

1. Different age groups have different discontinuation rates for all methods of contraception. Adolescents are more likely to refuse to use contraception, while older women have higher rates of satisfaction with family planning methods.

2. The socioeconomic status of women correlates with discontinuation chances, with poorer women being at higher risk of abandoning contraception.

3. Barrier methods, injections and IUD, implemented through public sector, are characterized by a shorter duration of use than the same methods implemented through private sector institutions.

\section{Conclusion}

The study shows that FPPs have a mixed effect on the method mix in developing countries. Shifts towards particular methods are more likely to occur in early programmes, while programmes implemented in subsequent periods show less dissimilarity in the eventual method mix. The nature of this correlation remains to be elucidated, but it can be assumed that the main factors in expanding the choice of methods are the development of medical technologies and the shift in the focus of the demographic policy of developing countries from reducing fertility to protecting reproductive health.

A significant finding for programme users is that in developing countries with family planning programmes, the poorest groups of the younger reproductive age are the most vulnerable and prone to rejecting contraception, regardless of method. At the same time, contraceptives show a shorter duration of use when sold through the public sector in comparison with the private one. This may indicate, among other things, a higher level of trust and involvement in the private sector or shortages in supply in the public sector.

When interpreting the results, it is important to realize that the study did not take into account the male population and the methods they use, and also that estimates of the discontinuation rates are based on survey data that are not supported by any clinical methods and may inaccurately reflect the real situation. In addition, discontinuation rates include contraceptive misfire, which is an exogenous factor that influences the user's choice, and the model for testing Hypothesis 2 does not include a variable that indicates the number of children a woman has already given birth to. 
The results of this study may indicate the need to centralize measures for the protection of reproductive health through uniting the efforts of FPPs and the medical community. This is mainly necessary to overcome information barriers both among the population and among medical personnel. The main focus here can be on retraining and professional development programmes for medical workers regarding contraceptive methods provided by FPPs. In the long term, this will reduce the adherence of suppliers to certain methods (method-bias). Service users will receive more detailed and reliable information about the medical contraindications and side effects of the various methods, which will expand their understanding of the contraceptive choice. This proposal is largely based on the thesis that users tend to underestimate the effectiveness of lesser-known and less frequently used methods (Fertility and family planning... 2016).

The introduction of regulations on the informational and qualitative separation of FPP users by age categories will also reduce the discontinuation rates for certain methods. Regardless of the country of implementation of the programme, it is necessary to take into account the age and other socio-demographic characteristics of users. In many ways, this will reduce the indicators of unmet need for high-quality family planning information among the young population.

For reduction in the frequency of discontinuation for certain contraceptive methods it is also important to consider integrating private sector interventions with public FPPs on the basis of a common centre, taking into account user needs. However, the relevant activities require consideration of additional factors, including sources of funding.

\section{Reference list}

Ali MM, Cleland JG, Shah IH (2012) Causes and Consequences of Contraceptive Discontinuation: Evidence from 60 Demographic and Health Surveys. Geneva: World Health Organization. URL: https://apps.who.int/iris/handle/10665/75429

Bertrand JT, Rice J, Sullivan TM, Shelton J (2000) Skewed Method Mix: A Measure of Quality in Family Planning Programs. USAID: MEASURE Evaluation. URL: https://www.measureevaluation.org/ resources/publications/wp-00-23.html

Bongaarts J (1978) A Framework for Analyzing the Proximate Determinants of Fertility. Population and Development Review: 4(1): 105-38. https://doi.org/10.2307/1972149

Bradley S, Polis C, Bankole A, Croft T (2019) Global Contraceptive Failure Rates: Who Is Most at Risk? Studies in Family Planning: 50(1): 3-24. URL: https://www.ncbi.nlm.nih.gov/pmc/articles/ PMC6594038/

Davis K, Blake J (1956) Social Structure and Fertility: An Analytic Framework. Economic Development and Cultural Change: 4(3): 211-35. URL: http://www.jstor.org/stable/1151774

Gipson JD, Koenig MA, Hindin MJ (2008) The effects of unintended pregnancy on infant, child, and parental health: A review of the literature. Studies in Family Planning: 39(1): 18-38. https://doi. org/10.1111/j.1728-4465.2008.00148.x

Morris L (2000) History and current status of reproductive health surveys at CDC. American Journal of Preventive Medicine: 19(1) Suppl.: 31-4. https://doi.org/10.1016/S07493797(00)00176-8

Pariani S, Heer DM, Van Arsdol MD Jr (1991) Does Choice Make a Difference to Contraceptive Use? Evidence from East Java. Studies in Family Planning: 22(6): 384-90. https://doi. org/10.2307/1966452 
Polis CB, Bradley S, Bankole A, Onda T, Croft T, Singh S (2016) Contraceptive failure rates in the developing world: An analysis of demographic and health survey data in 43 countries. NY: Guttmacher Institute. URL: https://www.guttmacher.org/report/contraceptive-failure-rates-in-developing-world

Rabe-Hesketh S, Skrondal A (2012) Multilevel and Longitudinal Modeling Using Stata / 3rd edition. StataCorp LP: Stata Press. URL: https://www.stata-press.com/books/multilevel-longitudinal-modeling-stata/

Ross J, Stover J (2013) Use of modern contraception increases when more methods become available: analysis of evidence from 1982-2009. Global Health: Science and Practice: 1(2): 203-12. https:// doi.org/10.9745/GHSP-D-13-00010

Rozhdaemost' i planirovanie sem'i: mneniya, ustanovki, motivatsiya [Fertility and family planning: opinions, attitudes, motivation] (2016) Seriya «Kachestvennye issledovaniya v ehkonomike i demografiI» [Qualitative research in economics and demography

Series] / IE Kalabikhina, IA Troitskaya (eds). Moscow: Faculty of Economics, Lomonosov Moscow State University. URL: https://www.econ.msu.ru/sys/raw.php?o=36371\&p=attachment (in Russian)

Sedgh G, Ashford LS, Hussain R (2016) Unmet Need for Contraception in Developing Countries: Examining Women's Reasons for Not Using a Method. NY: Guttmacher Institute. URL: https://www. guttmacher.org/report/unmet-need-for-contraception-in-developing-countries

Seltzer JR (2002) The Origins and Evolution of Family Planning Programs in Developing Countries. Santa Monica: RAND Corporation. URL: https://www.rand.org/pubs/monograph_reports/ MR1276.html

United Nations (1995) Report of the International Conference on Population and Development, Cairo, September 1994. A/CONF.171/13/Rev.1. New York: UN. URL: https://www.unfpa.org/sites/default/files/event-pdf/icpd_eng_2.pdf

World Health Organization (1994) Contraceptive Method Mix: Guidelines for Policy and Service Delivery. Geneva: World Health Organization. URL: https://apps.who.int/iris/handle/10665/39357

\section{Other data sources}

Demographic and Health Surveys (DHS). Bangladesh 2014. URL: https://dhsprogram.com/publications/publication-fr311-dhs-final-reports.cfm (accessed December 7, 2020)

Demographic and Health Surveys (DHS). Colombia 2000. URL: https://dhsprogram.com/publications/publication-fr114-dhs-final-reports.cfm (accessed December 9, 2020)

Demographic and Health Surveys (DHS). India 2015-16. URL: https://dhsprogram.com/publications/ publication-fr339-dhs-final-reports.cfm (accessed December 7, 2020)

Demographic and Health Surveys (DHS). Philippines 2017. URL: https://www.dhsprogram.com/publications/publication-FR347-DHS-Final-Reports.cfm (accessed December 15, 2020)

Demographic and Health Surveys (DHS). Senegal 2010-11. URL: https://dhsprogram.com/publications/publication-FR258-DHS-Final-Reports.cfm (accessed December 9, 2020)

Demographic and Health Surveys (DHS). Zimbabwe 2015. URL: https://dhsprogram.com/publications/publication-fr322-dhs-final-reports.cfm (accessed December 9, 2020)

The World Bank. World Development Indicators. URL: https://databank.worldbank.org/reports.aspx? source $=2 \&$ series $=$ NY.GNP.PCAP.CD\&country $=($ February 17, 2021 $)$

World Contraceptive Use 2020. United Nations, Department of Economic and Social Affairs, Population Division. URL: https:/www.un.org/en/development/desa/population/publications/dataset/ contraception/wcu2020.asp (December 9, 2020) 
World Health Organization. Family Planning. (n.d.) URL: https://www.who.int/health-topics/contraception\#tab=tab_1 (May 7, 2021)

World Health Organization. General practitioners (PP) per 100 000. URL: https://gateway.euro.who. int/en/indicators/hfa_507-5290-general-practitioners-pp-per-100-000/ (Ferbruary 17, 2021)

World Religion Database. URL: https://worldreligiondatabase.org (accessed March 1, 2021)

\section{Information about the author}

- Lilia Vladimirovna Boglaeva, Master student at the Faculty of Economics, Lomonosov Moscow State University. E-mail: lipali17@gmail.com 


\section{Appendix}

Table A1. Proportion of users of selected contraceptive methods by country and the Index of Dissimilarity of the method mix

\begin{tabular}{|c|c|c|c|c|c|c|c|c|}
\hline Country & Year & ID & $\begin{array}{c}\text { Female } \\
\text { steril- } \\
\text { ization }\end{array}$ & Pills & Injections & IUD & $\begin{array}{c}\text { Barrier } \\
\text { meth- } \\
\text { ods }\end{array}$ & $\begin{array}{c}\text { Tradi- } \\
\text { tional } \\
\text { methods }\end{array}$ \\
\hline \multicolumn{9}{|l|}{ Latin America } \\
\hline Bolivia & 2016 & 8.68 & 9.7 & 3.9 & 12.0 & 6.8 & 6.8 & 21.3 \\
\hline Brazil & 2013 & 9.43 & 21.4 & 34.2 & 5.3 & 2.0 & 10.3 & 2.5 \\
\hline Guatemala & 2015 & 11.15 & 21.0 & 3.3 & 16.6 & 1.5 & 3.8 & 11.7 \\
\hline $\begin{array}{l}\text { Dominican } \\
\text { Republic }\end{array}$ & 2014 & 16.70 & 40.7 & 17.8 & 4.3 & 2.5 & 1.4 & 1.5 \\
\hline Colombia & 2016 & 11.70 & 35.0 & 7.0 & 14.2 & 4.7 & 5.8 & 5.0 \\
\hline Costa Rica & 2015 & 10.47 & 25.5 & 5.3 & 9.2 & 3.2 & 9.2 & 2.8 \\
\hline Cuba & 2014 & 12.91 & 24.5 & 7.3 & 0.6 & 23.8 & 15.5 & 1.6 \\
\hline Mexico & 2018 & 13.40 & 37.1 & 2.5 & 3.7 & 11.4 & 7.6 & 3.3 \\
\hline Paraguay & 2016 & 9.00 & 8.8 & 19.0 & 21.3 & 6.1 & 10.4 & 1.9 \\
\hline Peru & 2018 & 10.00 & 9.6 & 7.4 & 18.4 & 2.2 & 13.9 & 21.3 \\
\hline Ecuador & 2012 & 8.48 & 32.3 & 11.1 & 10.8 & 5.1 & 5.4 & 8.4 \\
\hline \multicolumn{9}{|l|}{ Asia } \\
\hline Bangladesh & 2014 & 10.94 & 4.6 & 27.0 & 12.4 & 0.6 & 6.4 & 8.4 \\
\hline Vietnam & 2016 & 12.37 & 1.6 & 14.7 & 1.3 & 36.5 & 11.9 & 11.1 \\
\hline India & 2016 & 15.18 & 36.0 & 4.1 & $\ldots$ & 1.5 & 5.6 & 5.7 \\
\hline Indonesia & 2018 & 15.38 & 1.9 & 10.5 & 28.9 & 4.2 & 3.9 & 1.3 \\
\hline Iran & 2011 & 4.62 & 14.2 & 15.1 & 3.5 & 8.1 & 13.8 & 21.7 \\
\hline Iraq & 2018 & 9.51 & 3.0 & 16.0 & 3.9 & 8.8 & 3.2 & 16.7 \\
\hline Malaysia & 2014 & 6.69 & 6.9 & 13.2 & 4.9 & 2.7 & 5.6 & 17.9 \\
\hline Pakistan & 2018 & 8.65 & 8.8 & 1.7 & 2.5 & 2.1 & 9.2 & 9.2 \\
\hline Thailand & 2016 & 12.13 & 24.3 & 32.8 & 14.0 & 0.4 & 2.5 & 2.8 \\
\hline Turkey & 2018 & 11.01 & 10.4 & 4.8 & 1.0 & 13.7 & 19.1 & 21.0 \\
\hline Philippines & 2017 & 8.60 & 7.4 & 20.9 & 5.0 & 3.5 & 1.7 & 14.0 \\
\hline \multicolumn{9}{|l|}{ Africa } \\
\hline Algeria & 2013 & 18.42 & 0.5 & 43.0 & 0.1 & 2.2 & 1.9 & 7.6 \\
\hline Burundi & 2017 & 17.14 & 0.5 & 1.7 & 11.6 & 0.9 & 1.2 & 6.1 \\
\hline Ghana & 2017 & 11.44 & 1.9 & 4.3 & 8.2 & 0.8 & 1.1 & 5.8 \\
\hline Egypt & 2014 & 16.52 & 1.2 & 16.0 & 8.5 & 30.1 & 0.5 & 1.6 \\
\hline Zambia & 2018 & 17.29 & 1.5 & 7.6 & 25.6 & 0.7 & 3.0 & 2.4 \\
\hline Zimbabwe & 2015 & 18.51 & 0.8 & 40.9 & 9.6 & 0.6 & 3.8 & 1.0 \\
\hline Cameroon & 2018 & 13.85 & 0.3 & 1.1 & 3.7 & 0.9 & 5.2 & 4.3 \\
\hline
\end{tabular}




\begin{tabular}{lcccccccc}
\hline \multicolumn{1}{c}{ Country } & Year & ID & $\begin{array}{c}\text { Female } \\
\text { steril- } \\
\text { ization }\end{array}$ & Pills & Injections & IUD & $\begin{array}{c}\text { Barrier } \\
\text { meth- } \\
\text { ods }\end{array}$ & $\begin{array}{c}\text { Tradi- } \\
\text { tional } \\
\text { methods }\end{array}$ \\
\hline Liberia & 2016 & 19.45 & 0.9 & 4.9 & 18.9 & 0.3 & 1.3 & 1.0 \\
Madagascar & 2018 & 20.42 & 0.5 & 4.3 & 26.4 & 1.1 & 0.3 & 4.0 \\
Malawi & 2016 & 17.59 & 10.9 & 2.4 & 30.0 & 1.1 & 1.9 & 1.1 \\
Mali & 2018 & 15.15 & 0.4 & 2.2 & 5.8 & 1.0 & 0.1 & 0.8 \\
Mozambique & 2015 & 16.21 & 0.2 & 6.4 & 13.4 & 0.8 & 1.5 & 1.8 \\
Namibia & 2013 & 15.38 & 6.4 & 7.0 & 26.8 & 1.2 & 12.0 & 0.8 \\
Nigeria & 2018 & 19.24 & 0.1 & 3.9 & 3.4 & 0.1 & 0.0 & 0.5 \\
Tanzania & 2016 & 10.62 & 3.4 & 5.5 & 12.6 & 0.9 & 2.4 & 6.4 \\
Senegal & 2017 & 13.97 & 0.4 & 4.4 & 10.4 & 2.2 & 0.7 & 1.6 \\
Tunisia & 2018 & 15.94 & 1.3 & 18.9 & 0.7 & 21.3 & 1.0 & 6.1 \\
Central African & 2011 & 12.97 & 0.2 & 5.9 & 0.5 & 0.0 & 2.3 & 3.1 \\
Republic & & & & & & & & \\
\hline Average & & $\mathbf{1 3 . 1 8}$ & & & & & & \\
\hline
\end{tabular}

Source: compiled by the author based on (World Contraception Use 2020)

Table A2. Regression results: factors of changes in the method mix in various model specifications

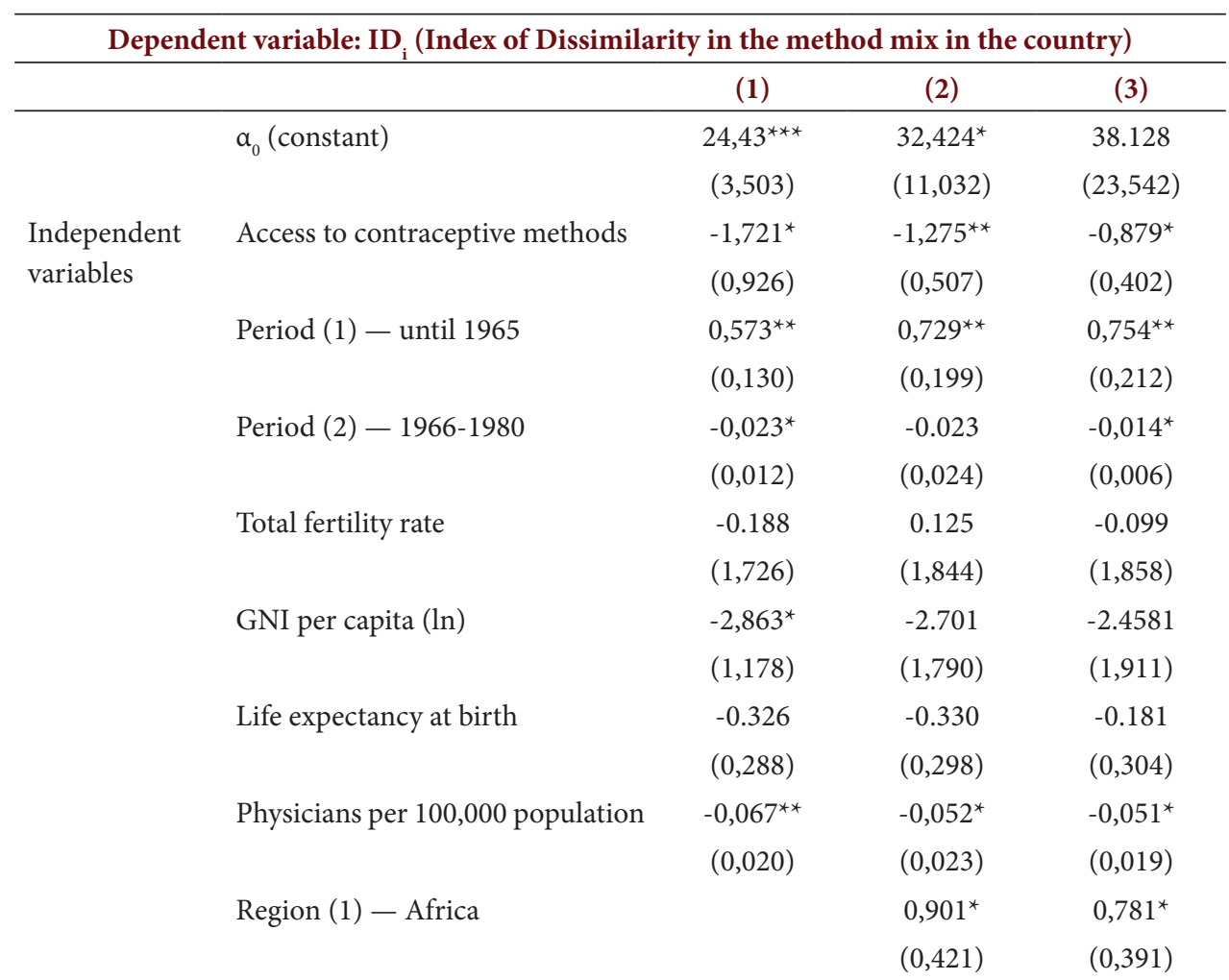




\begin{tabular}{|c|c|c|c|c|}
\hline \multicolumn{5}{|c|}{ Dependent variable: $\mathrm{ID}_{\mathrm{i}}$ (Index of Dissimilarity in the method mix in the country) } \\
\hline & & (1) & (2) & (3) \\
\hline \multirow{10}{*}{$\begin{array}{l}\text { Independent } \\
\text { variables }\end{array}$} & Region (2) - Latin America & & $-1,467^{\star *}$ & $-1,356^{\star * \star}$ \\
\hline & & & $(0,628)$ & $(0,132)$ \\
\hline & Religion (1) - Islam & & & $0,605^{*}$ \\
\hline & & & & $(0,274)$ \\
\hline & Religion (2) - Christianity & & & 0.308 \\
\hline & & & & $(0,601)$ \\
\hline & Religion (3) - other & & & 0.794 \\
\hline & & & & $(0,679)$ \\
\hline & Adjusted & 0.065 & 0.090 & 0.178 \\
\hline & $\mathrm{N}$ & 34 & 34 & 34 \\
\hline
\end{tabular}

Notes: $\mathrm{N}$ is the number of observations. Standard errors are indicated in parentheses.

Significance: ${ }^{\star} \mathrm{p}<0,1 ;{ }^{* *} \mathrm{p}<0,05 ;{ }^{* *} \mathrm{p}<0,01$.

Period (0) - 1981 and later, reference category

Region (0) - Asia, reference category

Religion (0) - Catholicism, reference category

Source: author's estimates based on (World Contraceptive Use 2020; United States Agency for International Development; World Bank; World Health Organizatio; World Religion Database). 


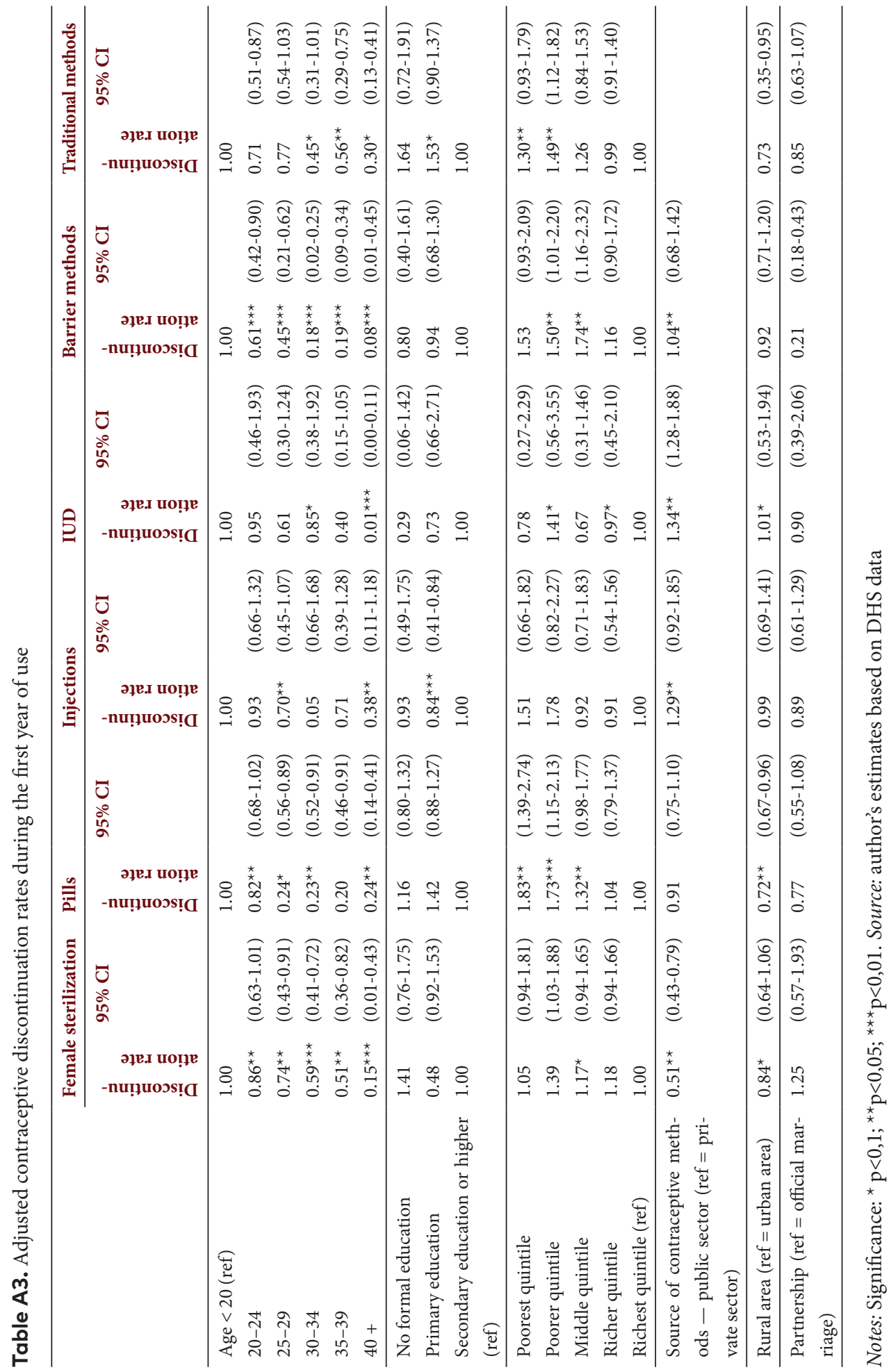

